\title{
Role of Endorectal Magnetic Resonance Spectroscopic Imaging in Two Different Gleason Scores in Prostate Cancer
}

\author{
Rajakumar Nagarajan Daniel Margolis Tim McClure Steve Raman \\ M. Albert Thomas \\ Department of Radiological Sciences, University of California, Los Angeles, Calif., USA
}

\section{Key Words}

Magnetic resonance spectroscopic imaging • Prostate cancer $\cdot$ Choline groups $\cdot$ Citrate $\cdot$ Creatine

\begin{abstract}
Objective: The major goal of the work was to record threedimensional magnetic resonance spectroscopic imaging (MRSI) and to compare metabolite ratios between different Gleason scores (GS). Materials and Methods: MRSI localized by endorectal coil-acquired point-resolved spectroscopy was performed in 14 men with prostate cancer of GS 6 ( $n=$ $7)$ and $7(n=7)$ using a 1.5-tesla MRI scanner. Results: The ratio of (choline + creatine)/citrate was increased with an increase of GS, i.e. $0.590 \pm 0.171$ in the target lesion and 0.321 \pm 0.157 in the contralateral region of patients with a GS of 6 as opposed to $1.082 \pm 0.432$ in the target lesion and 0.360 \pm 0.243 in the contralateral region of patients with a GS of 7 . Conclusion: Our pilot results demonstrated that MRSI was an additional biochemical tool which is complementary to the current imaging modalities for early diagnosis and therapeutic management of prostate cancer.
\end{abstract}

Copyright $\odot 2011$ S. Karger AG, Basel
(C) 2011 S. Karger AG, Basel

1011-7571/11/0205-0444\$38.00/0

Accessible online at: www.karger.com/mpp

\section{Introduction}

Prostate cancer is the most common noncutaneous malignancy and the second leading cause of death from cancer, after lung cancer, in American men [1]. As with any cancer, if it is advanced or left untreated in early stages, it can eventually spread through the blood and lymph network to other organs. Fortunately, prostate cancer tends to be slow-growing compared to other cancers. The term 'grade' describes how closely the tumor resembles normal prostate tissue. The most widespread way of grading prostate cancer is called the Gleason system and this system uses a Gleason score (GS) of 2-10 to grade prostate cancer, where higher grades represent more aggressive tumors [2-4]. The GS offers a good clue of the tumor's behavior as the prostate tumor with a low GS is likely to be slow-growing, while one with a high score is more likely to grow aggressively or to have already spread outside the prostate (metastasized).

Magnetic resonance imaging (MRI) and magnetic resonance spectroscopic imaging (MRSI) enable anatomic and metabolic evaluation of the prostate gland. The MRSI is a powerful technique for local evaluation of prostate cancer growth and aggressiveness. MRSI facilitates the demonstration of normal and altered tissue metabolism,

M. Albert Thomas

Radiological Sciences, David Geffen School of Medicine at UCLA 10833 Le Conte Avenue

Los Angeles, CA 90095-1721 (USA)

Tel. +1 310206 4191, E-Mail athomas@mednet.ucla.edu 
and is therefore different from other imaging methods that only assess abnormalities of structure. The primary MRSI technique that is currently available commercially utilizes the point-resolved spectroscopy sequence [5], with spectral spatial pulses for lipid suppression [6-8]. In particular, endorectal MRI and MRSI have shown considerable promise in the evaluation of tumor extent and aggressiveness in patients with biopsy-proven prostate cancer [9-11] and might be valuable in tumor diagnosis.

Cancer tissue can appear in any place in the prostate, and so the use of a three-dimensional (3D) MRSI method to cover the whole prostate is necessary [12]. MRI may improve the staging of prostate cancer compared with clinical evaluation alone, computer tomography, or transrectal ultrasound, as it allows simultaneous and detailed assessment of prostatic, periprostatic, and pelvic anatomy. Earlier reports suggesting a limited applicability of MRI did not incorporate MRSI or the use of endorectal coils, and they used sequences and equipment that were not up to current standards. The value of MRSI to detect and localize cancer in the transition zone of the prostate has been reported $[13,14]$. Prostate cancer has been shown to be characterized by a decreased signal of citrate (Cit) and an increased signal of choline (Cho)-containing compounds. Therefore, a commonly used marker for cancer tissue is the ratio of [Cho + creatine (Cr)]/Cit. The purpose of the study was to record 3D MRSI and to compare metabolite ratios using spectroscopic imaging data between 2 different Gleason scores $(3+3=6$ vs. $4+3=7)$.

\section{Materials and Methods}

The entire protocol was approved by the Institutional Review Board, and informed consent was obtained from each patient. $\mathrm{Pa}$ tient selection was limited to GS 6 or 7 and prostatectomy. Fourteen men $[\mathrm{n}=7$ with a GS $(3+3)$ and $n=7$ with a GS $(4+3)]$ underwent radical retropubic prostatectomy, and their pathologies were subsequently analyzed. These patients were scanned using a 1.5-tesla Siemens (Siemens Medical Solution, Erlangen, Germany) MRI scanner with an endorectal coil. The protocol combining MRI and MRS was performed at least 8 weeks after transrectal ultrasound-guided sextant biopsy. MRI included $\mathrm{T}_{2}$-weighted images acquired with a fast spin-echo sequence with: repetition time $(\mathrm{TR})=3,800 \mathrm{~ms}$, effective echo time $(\mathrm{TE})=101 \mathrm{~ms}$, slice thickness $=3 \mathrm{~mm}$, field of view $=140 \mathrm{~mm}$, and matrix size $=256$ $\times 256$. The ages of the patients ranged from 52 to 78 years, and the patients had 2 different GS: $3+3$ (mean \pm SD, $56.8 \pm 7.9$ years) and $4+3$ (mean $\pm \mathrm{SD}, 64.8 \pm 8.6$ years). The mean and standard deviation of prostate-specific antigen value for the patients with a GS of $3+3$ was $7.2 \pm 2.5 \mathrm{ng} / \mathrm{ml}$. For patients with a GS of $4+3$, it was $13.5 \pm 3.1 \mathrm{ng} / \mathrm{ml}$.

MR Spectroscopy of Human Prostate Cancer
MRSI was performed in all patients, including water- and fatsuppressed acquisition. The parameters were: TR/TE/Avg/BW = $700 \mathrm{~ms} / 120 \mathrm{~ms} / 6 \mathrm{~ms} / 1,300 \mathrm{~Hz}$, and 512 spectral data points, where TR, TE, Avg, and BW represent repetition time, echo time, averages and spectral bandwidth. The field of view was $80 \times 80 \times 80$ $\mathrm{mm}^{3}$ with a raw matrix size of $512 \times 12 \times 12 \times 12$. A point-resolved spectroscopy pulse sequence was used to acquire the proton MR spectra from a volume of interest of $55 \times 40 \times 40 \mathrm{~mm}^{3}$. Outer volume lipid suppression was achieved using eight $3-\mathrm{cm}$ slab saturation pulses around the volume of interest. Water and fat resonances were suppressed using two 12.6-ms dual-frequency selective MEGA pulses [15] with crusher gradients. A TE of 120 ms was used for optimal Cit detection.

The spectroscopy software on the MR scanner provided by the manufacturer was used to evaluate the $(\mathrm{Cho}+\mathrm{Cr}) / \mathrm{Cit}$ ratio. For 3D MRSI postprocessing, each spectrum was Fourier transformed, frequency-, phase-, and baseline-corrected, and peaks of Cit, Cho and $\mathrm{Cr}$ were subsequently fitted. Hamming filter was used for the MRSI spatial dimensions of the data. For the statistical analysis, the Student $t$ test was used to compare the ratios between different GS, and a p value of less than 0.05 was considered to indicate a significant difference. A radiologist (D.M.) and a physicist (M.A.T.), both with more than 10 years of experience in analyzing prostate endorectal MRI and MRSI data, interpreted the imaging studies using established morphologic and metabolic criteria for the MRI and MRSI evaluation of prostate cancer. The spectroscopist evaluated the MRSI data set and provided the location and number of suspicious voxels to the radiologist, who integrated the MRSI information with the MRI data and provided a final reading for each study. In the decision status for classifying voxels as noncancerous or malignant, the voxels were first broken up according to their GS and noncancerous regions. If the Cit peak was lower than the Cho peak or was undetectable, the voxel was determined to be malignant. If the Cit peak was higher than the Cho peak, the voxel was considered noncancerous for (Cho + $\mathrm{Cr}) /$ Cit smaller than 0.37 and malignant for $(\mathrm{Cho}+\mathrm{Cr}) / \mathrm{Cit}$ greater than 0.37 .

\section{Statistical Test}

The mean and standard deviation of $(\mathrm{Cho}+\mathrm{Cr}) / \mathrm{Cit}$ were calculated. Statistical analysis was conducted using the Student $t$ test between 2 different GS. A value of $\mathrm{p}<0.05$ was considered to be significant.

\section{Results}

The one-dimensional (1D) spectra extracted from the 3D MRSI data recorded in the affected and contralateral area of a 67-year-old prostate cancer patient with a GS of 6 $(3+3)$ are shown in figure $1 \mathrm{a}$ and $\mathrm{b}$, and the corresponding voxel locations are presented in figure $1 \mathrm{c}$ and $\mathrm{d}$. Similarly, the 1D spectra extracted from the 3D MRSI data recorded in the affected and contralateral area of a 70 -year-old prostate cancer patient with a GS of $7(4+3)$ are shown in figure $2 \mathrm{a}$ and $\mathrm{b}$. In prostate cancer patients with a GS of $3+3$, the $(\mathrm{Cho}+\mathrm{Cr}) /$ Cit ratios in the affected side were 
Fig. 1. Spectroscopic imaging of a 67-yearold prostate cancer patient with a GS $3+3$. a, b The 1D spectra extracted from the 3D MRSI data recorded in the affected and contralateral area. c, d The corresponding voxel locations.
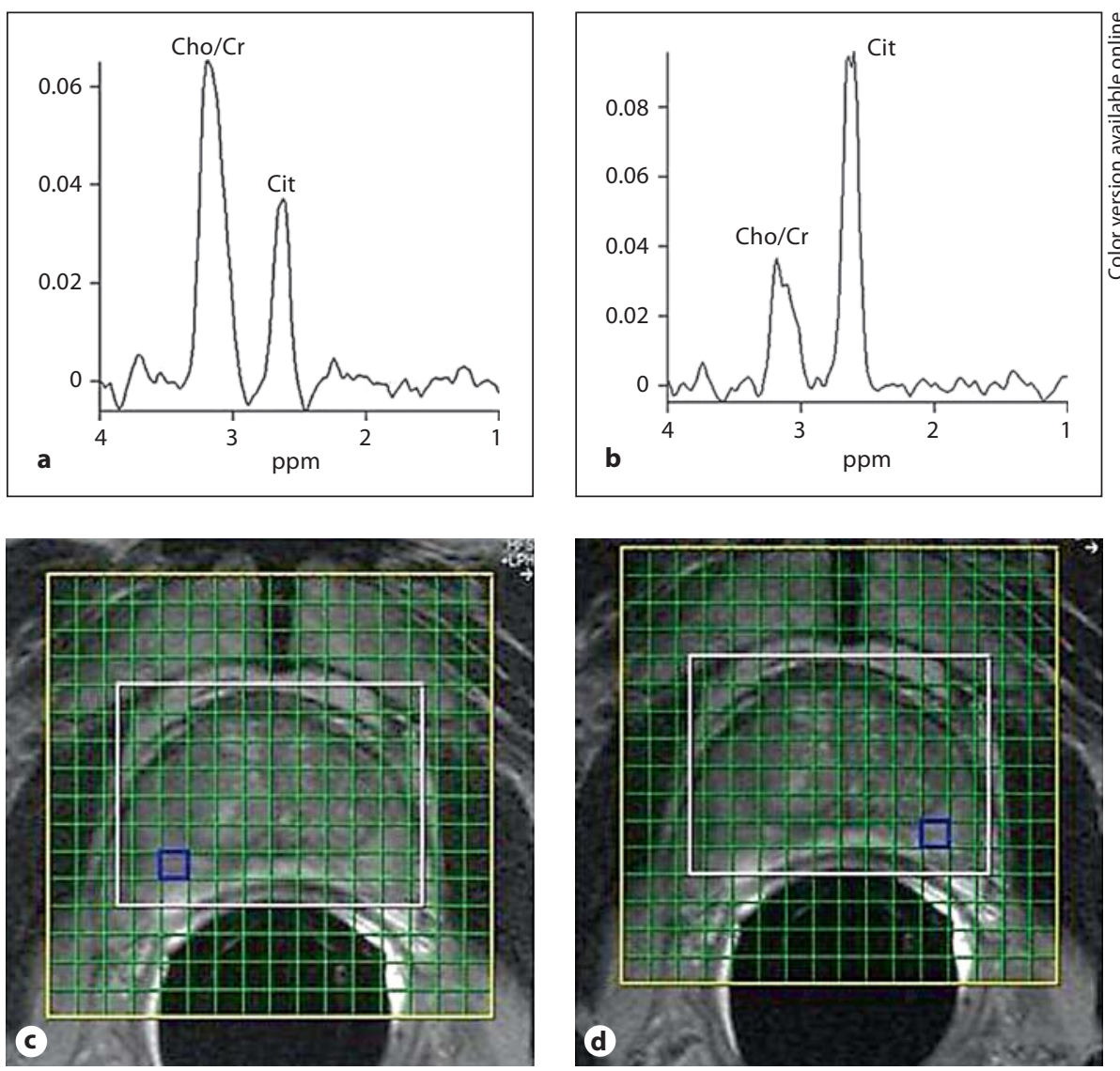

Table 1. Metabolite (Cho $+\mathrm{Cr}) / \mathrm{Cit}$ ratios calculated using the $3 \mathrm{D}$ MRSI data recorded in 2 different grades

\begin{tabular}{|c|c|c|}
\hline Location & $\begin{array}{l}\text { Contralateral } \\
\text { regions }\end{array}$ & $\begin{array}{l}\text { Lesion with } \\
\text { GS } 3+3(n=7)\end{array}$ \\
\hline \multicolumn{3}{|c|}{ GS of 6 (i.e. $3+3$ ) } \\
\hline Apex & $0.208 \pm 0.074$ & $0.522 \pm 0.066$ \\
\hline Midgland & $0.192 \pm 0.157$ & $0.377 \pm 0.328$ \\
\hline Base & $0.321 \pm 0.157$ & $0.590 \pm 0.171$ \\
\hline Location & $\begin{array}{l}\text { Contralateral } \\
\text { regions }\end{array}$ & $\begin{array}{l}\text { Lesion with } \\
\text { GS } 4+3(n=7)\end{array}$ \\
\hline \multicolumn{3}{|c|}{ GS of 7 (i.e. $4+3$ ) } \\
\hline Apex & $0.303 \pm 0.025$ & $0.580 \pm 0.134$ \\
\hline Midgland & $0.198 \pm 0.142$ & $0.442 \pm 0.174$ \\
\hline Base & $0.360 \pm 0.243$ & $1.082 \pm 0.432$ \\
\hline
\end{tabular}

Med Princ Pract 2011;20:444-448
$0.522 \pm 0.066,0.377 \pm 0.328$ and $0.590 \pm 0.171$ in the apex, midgland and base regions, respectively. In contrast, these ratios in the apex, midgland and base regions of the contralateral side were $0.208 \pm 0.074,0.192 \pm 0.157$ and $0.321 \pm 0.157$, respectively. On the other hand, these ratios in prostate cancer patients with a GS of $4+3$ were as follows: $0.580 \pm 0.134,0.442 \pm 0.174$ and $1.082 \pm 0.432$ in the apex, midgland and base regions of the affected side and $0.303 \pm 0.025,0.198 \pm 0.142$ and $0.360 \pm 0.243$ in the contralateral side, as summarized in table 1 . There were no statistically significant changes observed in the $(\mathrm{Cho}+\mathrm{Cr}) /$ Cit ratios with GS. However, a trend was visible, i.e. GS 7 had a higher $(\mathrm{Cho}+\mathrm{Cr}) /$ Cit ratio compared to GS 6 .

\section{Discussion}

Endorectal MRI and MRSI facilitate improved diagnosis of prostate cancer in patients with 2 different GS. The ratio of $(\mathrm{Cho}+\mathrm{Cr}) / \mathrm{Cit}$ is capable of distinguishing between healthy and cancerous prostate tissues. MR 
Fig. 2. Spectroscopic imaging of a 70-yearold prostate cancer patient with a GS $4+3$. a, b The $1 \mathrm{D}$ spectra extracted from the 3D MRSI data recorded in the affected and contralateral area. c, d The corresponding voxel locations.
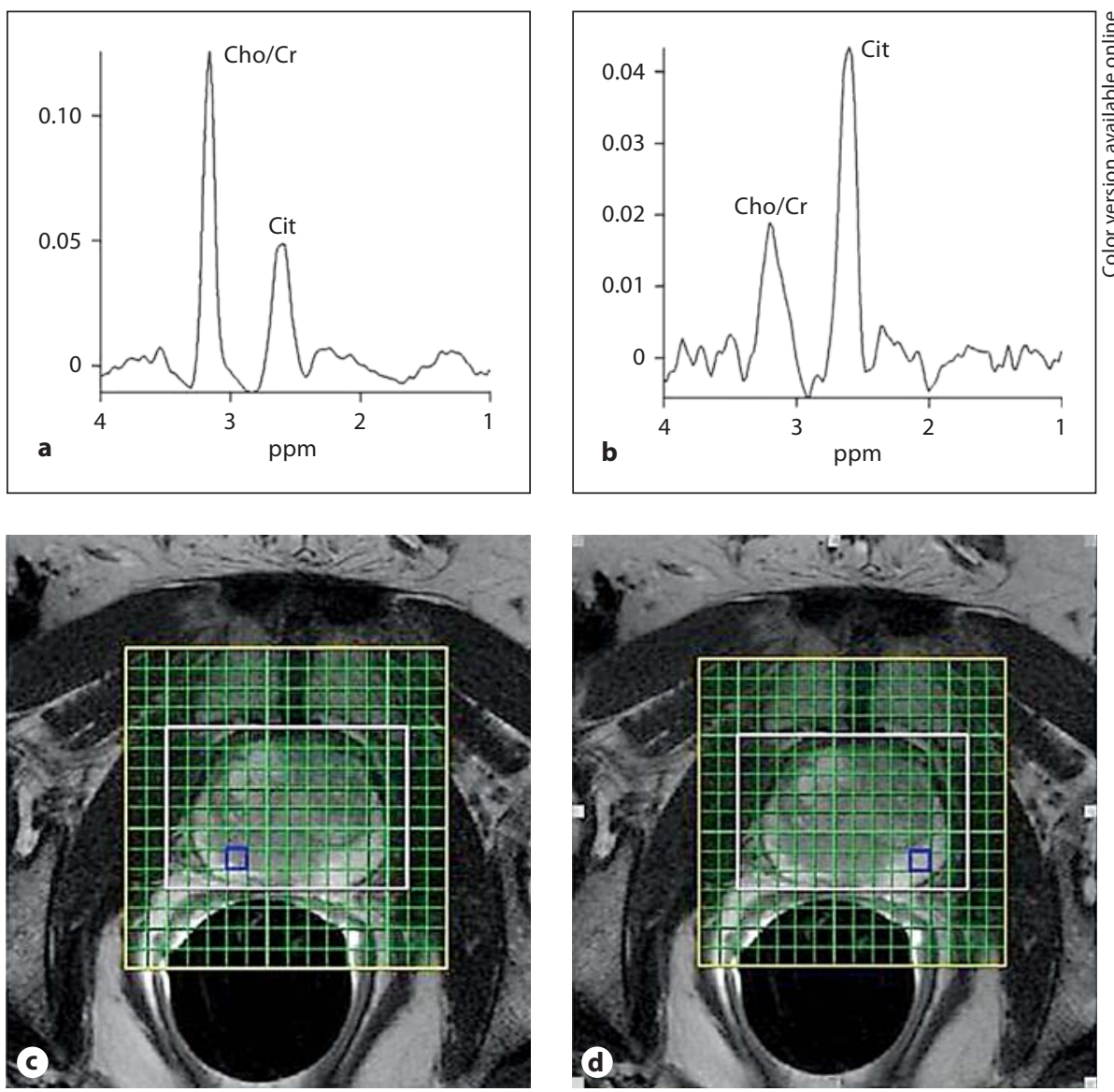

spectroscopy of the prostate is a noninvasive approach for the detection of prostate cancer, and the potential of MR spectroscopy to identify intraprostatic cancer foci in addition to MRI with a high sensitivity and specificity has already been proven in several studies $[16,17]$. So far, the emphasis in MRSI of the prostate was placed on the peripheral zone [18] resulting from the fact that the signalto-noise ratio in the peripheral zone is superior to the central gland because the endorectal coil is positioned against the dorsal part of the prostate which contains the peripheral zone. Seventy percent of tumor nodules are present in the peripheral zone $[19,20]$. As the GS increased, the metabolite ratio of $(\mathrm{Cho}+\mathrm{Cr}) / \mathrm{Cit}$ also elevated. Numerous investigators have also found elevated Cho levels in tumors [21-23]. Since these compounds are anabolites (Cho and phosphocholine) and catabolites (glycerophosphocholine) of phosphatidylcholine, which is a major membrane phospholipid, it has been suggested that the elevated Cho level reflects an elevated cell proliferation rate, and there are some data to support this hypothesis [24]. Even though the metabolite ratio measured by MRSI did not show statistically significant changes, there are higher levels of Cho-containing metabolites in prostate cancers having higher Gleason grades, which agrees with a previous study [25]. There is an overlap between MRSI parameters at various GS levels, which may reflect methodological and physiological variations.

\section{Conclusion}

Our study showed that the metabolite ratio of (Cho + $\mathrm{Cr}$ )/Cit in MRSI measurement of prostate cancer increased with an increase of these 2 GS (GS $3+3$ and GS $4+3)$. MRSI has potential in noninvasive evaluation of prostate cancer aggressiveness.

\section{Acknowledgement}

This work was supported by an idea award from the US Army Prostate Cancer Research Program (No. W81XWH-04-1-0885). 


\section{References}

$>1$ Jemal A, Thun MJ, Ries LA, Howe HL, Weir $\mathrm{HK}$, Center MM, Ward E, Wu XC, Eheman C, Anderson R, Ajani UA, Kohler B, Edwards $\mathrm{BK}$ : Annual report to the nation on the status of cancer, 1975-2005, featuring trends in lung cancer, tobacco use, and tobacco control. J Natl Cancer Inst 2008; 100:1672-1694.

-2 Kattan MW, Eastham JA, Stapleton AMF, Wheeler TM, Scardino PT: A preoperative nomogram for disease recurrence following radical prostatectomy for prostate cancer. J Natl Cancer Inst 1998;90:766-771.

$>3$ Albertsen PC, Fryback DG, Storer BE, Kolon TF, Fine J: Long-term survival among men with conservatively treated localized prostate cancer. JAMA 1995;274:626-631.

-4 Gleason DF: Classification of prostatic carcinomas. Cancer Chemother Rep 1966;50: 125-128.

$>5$ Bottomley PA: Spatial localization in NMR spectroscopy in vivo. Ann NY Acad Sci 1987; 508:333-348.

6 Brown TR, Kincaid BM, Ugurbil K: NMR chemical shift imaging in three dimensions. Proc Natl Acad Sci USA 1982;79:3523-3526.

7 Star-Lack J, Nelson SJ, Kurhanewicz J, Huang LR, Vigneron DB: Improved water and lipid suppression for 3D PRESS CSI using RF band selective inversion with gradient dephasing (BASING). Magn Reson Med 1997; 38:311-321.

-8 Schricker AA, Pauly JM, Kurhanewicz J, Swanson MG, Vigneron DB: Dual-band spectral-spatial RF pulses for prostate MR spectroscopic imaging. Magn Reson Med 2001;46:1079-1087.

$>9$ Bostwick DG, Graham SD Jr, Napalkov P, Abrahamsson PA, di Sant'agnese PA, Algaba F, Hoisaeter PA, Lee F, Littrup P, Mostofi FK: Staging of early prostate cancer: a proposed tumor volume-based prognostic index. Urology 1993;41:403-411.
10 Coakley FV, Kurhanewicz J, Lu Y, Jones KD, Swanson MG, Chang SD, Carroll PR, Hricak $\mathrm{H}$ : Prostate cancer tumor volume: measurement by endorectal MR imaging and MR spectroscopic imaging. Radiology 2002;223: 91-97.

11 Scheidler J, Hricak H, Vigneron DB, Yu KK, Sokolov DL, Huang LR, Zaloudek CJ, Nelson SJ, Carroll PR, Kurhanewicz J: Prostate cancer: localization with three-dimensional proton MR spectroscopic imaging - clinicopathologic study. Radiology 1999;213:473480 .

12 Scheenen TW, Klomp DW, Röll SA, Fütterer JJ, Barentsz JO, Heerschap A: Fast acquisition-weighted three-dimensional proton MR spectroscopic imaging of the human prostate. Magn Reson Med 2004;52:80-88.

13 Zakian KL, Eberhardt S, Hricak H, ShuklaDave A, Kleinman S, Muruganandham M, Sircar K, Kattan MW, Reuter VE, Scardino PT, Koutcher JA: Transition zone prostate cancer: metabolic characteristics at $1 \mathrm{H} \mathrm{MR}$ spectroscopic imaging - initial results. Radiology 2003;229:241-247.

14 Akin O, Sala E, Moskowitz CS, Kuroiwa K, Ishill NM, Pucar D, Scardino PT, Hricak H: Transition zone prostate cancers: features, detection, localization, and staging at endorectal MR imaging. Radiology 2006;239: 784-792.

15 Mescher M, Tannus A, Johnson MO, Garwood M: Solvent suppression using selective echo dephasing. J Magn Reson A 1996;123: 226-229.

16 Kurhanewicz J, Vigneron DB, Hricak H, Narayan $\mathrm{P}$, Carroll $\mathrm{P}$, Nelson SJ: Three-dimensional H-1 MR spectroscopic imaging of the in situ human prostate with high (0.24-0.7 $\mathrm{cm}^{3}$ ) spatial resolution. Radiology 1996;198: 795-805.

17 Hasumi M, Suzuki K, Taketomi A, Matsui H, Yamamoto T, Ito K, Kurokawa K, Aoki J, Endo K, Yamanaka H: The combination of multi-voxel MR spectroscopy with MR imaging improve the diagnostic accuracy for localization of prostate cancer. Anticancer Res 2003;23:4223-4227.
18 Zakian KL, Sircar K, Hricak H, Chen HN, Shukla-Dave A, Eberhardt S, Muruganandham M, Ebora L, Kattan MW, Reuter VE, Scardino PT, Koutcher JA: Correlation of proton MR spectroscopic imaging with Gleason score based on step-section pathologic analysis after radical prostatectomy. Radiology 2005;234:804-814.

19 Chen ME, Johnston DA, Tang K, Babaian RJ, Troncoso P: Detailed mapping of prostate carcinoma foci: biopsy strategy implications. Cancer 2000;89:1800-1809.

20 McNeal JE, Redwine EA, Freiha FS, Stamey TA: Zonal distribution of prostatic adenocarcinoma: correlation with histologic pattern and distribution of spread. Am J Surg Pathol 1988;12:804-814

-21 Heesters MA, Kamman RL, Mooyaart EL, Go KG: Localized proton spectroscopy of inoperable brain gliomas: response to radiation therapy. J Neurooncol 1993;17:27-35.

22 Sijens PE, Knopp MV, Brunetti A, Wicklow K, Alfano B, Bachert P, Sanders JA, Stillman AE, Kett H, Sauter R: ${ }^{1} \mathrm{H}$ MR spectroscopy in patients with metastatic brain tumors: a multicenter study. Magn Reson Med 1995; 33:818-826.

23 Rutter A, Hugenholtz H, Saunders JK, Smith ICP: One-dimensional phosphorus-31 chemical shift imaging of human brain tumors. Invest Radiol 1995;30:359-366.

24 Smith TA, Eccles S, Ormerod MG, Tombs AJ, Titley JC, Leach MO: The phosphocholine and glycerophosphocholine content of an oestrogen-sensitive rat mammary tumour correlates strongly with growth rate. $\mathrm{Br} J$ Cancer 1991;64:821-826.

25 Swanson MG, Vigneron DB, Tabatabai ZL, Males RG, Schmitt L, Carroll PR, James JK, Hurd RE, Kurhanewicz J: Proton HR-MAS spectroscopy and quantitative pathologic analysis of MRI/3D-MRSI-targeted postsurgical prostate tissues. Magn Reson Med 2003;50:944-954. 